\title{
Addressing Korea's Long-Term Fiscal Challenges
}

\author{
Tarhan Feyzioğlu, Michael Skaarup, and \\ Murtaza Syed
}





\title{
IMF Working Paper
}

\author{
Asia and Pacific Department
}

\section{Addressing Korea's Long-Term Fiscal Challenges}

\author{
Prepared by Tarhan Feyzioğlu, Michael Skaarup, and Murtaza Syed ${ }^{1}$ \\ Authorized for distribution by Jerald Schiff
}

January 2008

\begin{abstract}
This Working Paper should not be reported as representing the views of the IMF. The views expressed in this Working Paper are those of the author(s) and do not necessarily represent those of the IMF or IMF policy. Working Papers describe research in progress by the author(s) and are published to elicit comments and to further debate.

Korea is on the verge of an unprecedented demographic shift. In coming decades, rapid aging will transform it from one of the youngest populations in the OECD to among the oldest in record time. In turn, this shift will put tremendous pressure on the pension system and health and long-term care expenditures. This paper evaluates the impact of population aging on the long-term fiscal position in Korea, and assesses potential policy responses using the IMF's Global Fiscal Model. The paper finds that the key to maintaining a sound long-run fiscal position is to act early and with a range of policy tools, including pension reform, tax base broadening (and, if necessary, rate hikes), improved tax administration and some expenditure reallocation.
\end{abstract}

JEL Classification Numbers: E62, F41, F47, H20, H30, H55, H63, J11, J26

Keywords: Korea, Aging, Simulation, Sustainability, Tax Reform, General Equilibrium Author’s E-Mail Address:tfeyzioglu@imf.org; mskaarup@imf.org and msyed@imf.org

\footnotetext{
${ }^{1}$ Tarhan Feyzioğlu and Murtaza Syed are with the Asia and Pacific Department, and Michael Skaarup is with the Fiscal Affairs Department of the IMF. We thank Jerald Schiff and Mark DeBroek for many helpful comments and suggestions.
} 


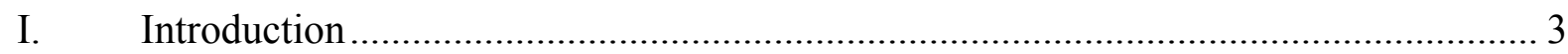

II. Demographic Change and Associated Expenditure Pressues ........................................ 4

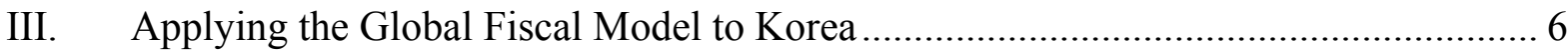

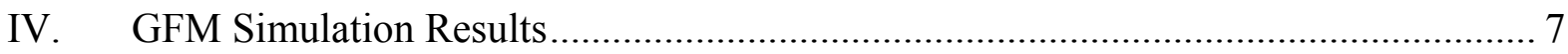

V. Policy Options for Achieving the Required Adjustment …………………….......... 16

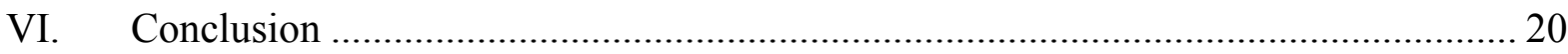

\section{Figures}

1. Demographic Developments in Korea and the G-7 Countries, 1950-2050 ….............. 5

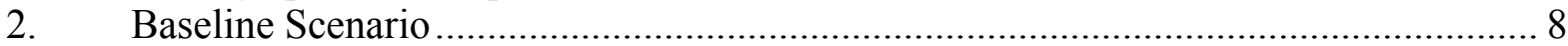

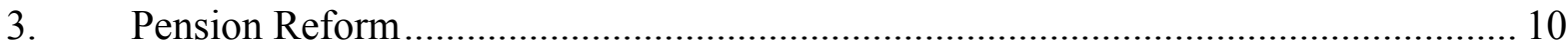

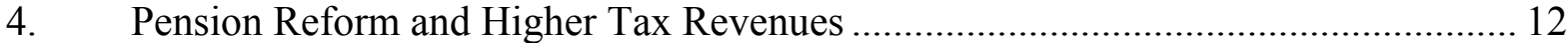

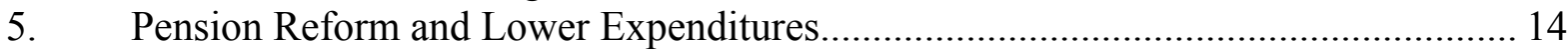

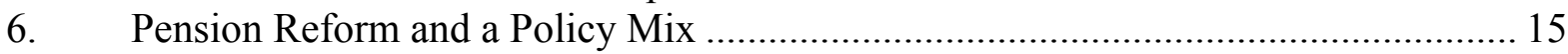

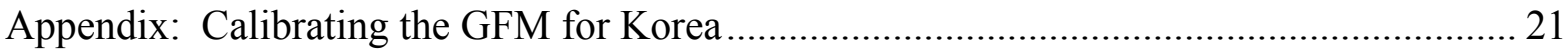

Appendix Tables

A.1. Korea: Key Macroeconomic Variables in the Initial Steady State ...........................22

A.2. Korea: Behavioral Assumptions and Key Parameters in the Initial Steady State....... 22

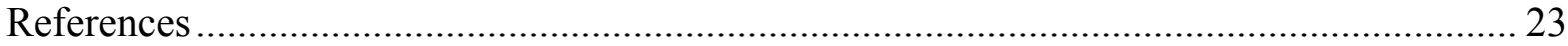




\section{INTRODUCTION}

Korea is on the verge of an unprecedented demographic shift, which will severely strain its public finances. Over coming decades, rapid aging is set to transform Korea from one of the youngest populations in the OECD to among the oldest in record time. This shift will put tremendous pressure on the pension system as well as health and long-term care spending.

This paper evaluates the impact of aging on the long-term fiscal position in Korea, and assesses potential policy responses using the IMF's Global Fiscal Model (GFM). The GFM is well suited for this task because, in addition to projecting long-term developments in the fiscal balance and public net asset positions, it simulates the impact of fiscal policy on the macroeconomy. The key results of the analysis are:

- Korea benefits from a number of favorable initial conditions compared to other economies facing age-related fiscal pressures, notably currently high rates of economic growth, considerable scope for increasing tax revenue, and a low level of public debt. These provide more degrees of freedom in dealing with age-related fiscal pressures.

- However, the unprecedented speed of its demographic transition and the confluence of long-term fiscal pressures that Korea faces, notably from the government's desire to significantly raise spending on the social safety net and potential reunification with North Korea, leave a relatively narrow window of opportunity.

- Although pressures will not show in the near term as the pension system continues to accumulate assets, age-related spending pressures will accelerate in the long term. In the absence of a policy response, both the fiscal deficit and public debt would balloon, the current account deficit would grow rapidly, and long-term growth would be constrained. To address these rising expenditure pressures will require a range of policies.

- Despite the large pressures, early action would imply that only modest measures are needed. The earlier these measures are taken, the smaller the required tax hikes or expenditure reductions and the smaller the declines in future consumption and investment. Moreover, early action will prevent large current account deficits, lower the long-run debt level and ensure superior long-term growth outcomes.

- In addition, the key to addressing these fiscal pressures and ensuring a sound long-run fiscal position is to act with a broad range of policy tools, including pension reform, tax base broadening (and, if necessary, rate hikes), improved tax administration and perhaps some expenditure reallocation. Implementing a combination of modest policies in these areas could be particularly attractive if making reforms in any one area would be difficult politically. The publication of a regular long-term fiscal report could help communicate underlying fiscal pressures to the public and build consensus for these reforms. 
The rest of the paper is organized as follows. Section II sets the stage by discussing Korea's demographic outlook and associated age-related expenditure pressures. Section III describes the IMF's Global Fiscal Model and its calibration to the Korean economy. Section IV uses the GFM to simulate the macroeconomic effects of a number of potential fiscal policy measures that could be used to place Korea's public finances on a sound footing over the long-term. Section $\mathrm{V}$ discusses more concrete policies and reforms that could help achieve the needed adjustment, and section VI concludes.

\section{Demographic Change And Associated Expenditure Pressures}

As a result of rising longevity and low fertility rates, Korea's demographic structure will experience extreme changes in the coming decades. The fertility rate-having fallen sharply from around 6 in 1960 to just over 1 -is among the lowest in the world and life-expectancy is projected to increase by around 7 years over the next half century or so (Figure 1). These changes will translate into an extraordinarily large increase in the old-age dependency ratio (the number of people aged 65 and above to the working-age population), from 13 percent in 2005 to 65 percent in 2050. In other words, while there are currently more than 7 persons of working age to support every older Korean citizen, there will then only be around $1 \frac{1}{2}$. This increased burden reflects a 33 percent decline in the working-age population, and a 230 percent increase in the elderly population. Although population developments in the G-7 countries show similar patterns, the magnitude of the changes is much less pronounced.

Given this demographic outlook, it is estimated that - absent a policy response - public agerelated expenditures could increase by as much as 13 percent of GDP by 2060 in Korea, reflecting a rise in pensions (including occupational pensions) ${ }^{2}$ of some $4-5$ percentage points of GDP ${ }^{3}$, and a rise in health and long-term care expenditure of 7-8 percentage points of GDP (OECD, 2006a; Yun, 2005). Reflecting the severity of population aging in Korea, the total projected increase is more than three times larger than in the average G7 economy. ${ }^{4}$

\footnotetext{
${ }^{2}$ In addition to the National Pension System, separate occupational pension schemes operate for government employees, private teachers and military personnel, and currently insure around 8 percent of the labor force.

${ }^{3}$ Based on Feyzioğlu (2006), Gruenwald (2003), and Moon (2003), adjusted to include the effects of the 2007 pension reform, which is discussed later.

${ }^{4}$ There are considerable uncertainties and complications associated with making long-term age-related expenditure projections for any economy, relating to demographic factors and underlying expenditure assumptions; the evolution of non-age-related expenditures; and the growth-interest rate differential. For a further discussion of aging in the G-7 countries see Hauner, Leigh and Skaarup (2007).
} 
Figure 1. Demographic Developments in Korea and the G-7 Countries, 1950-2050
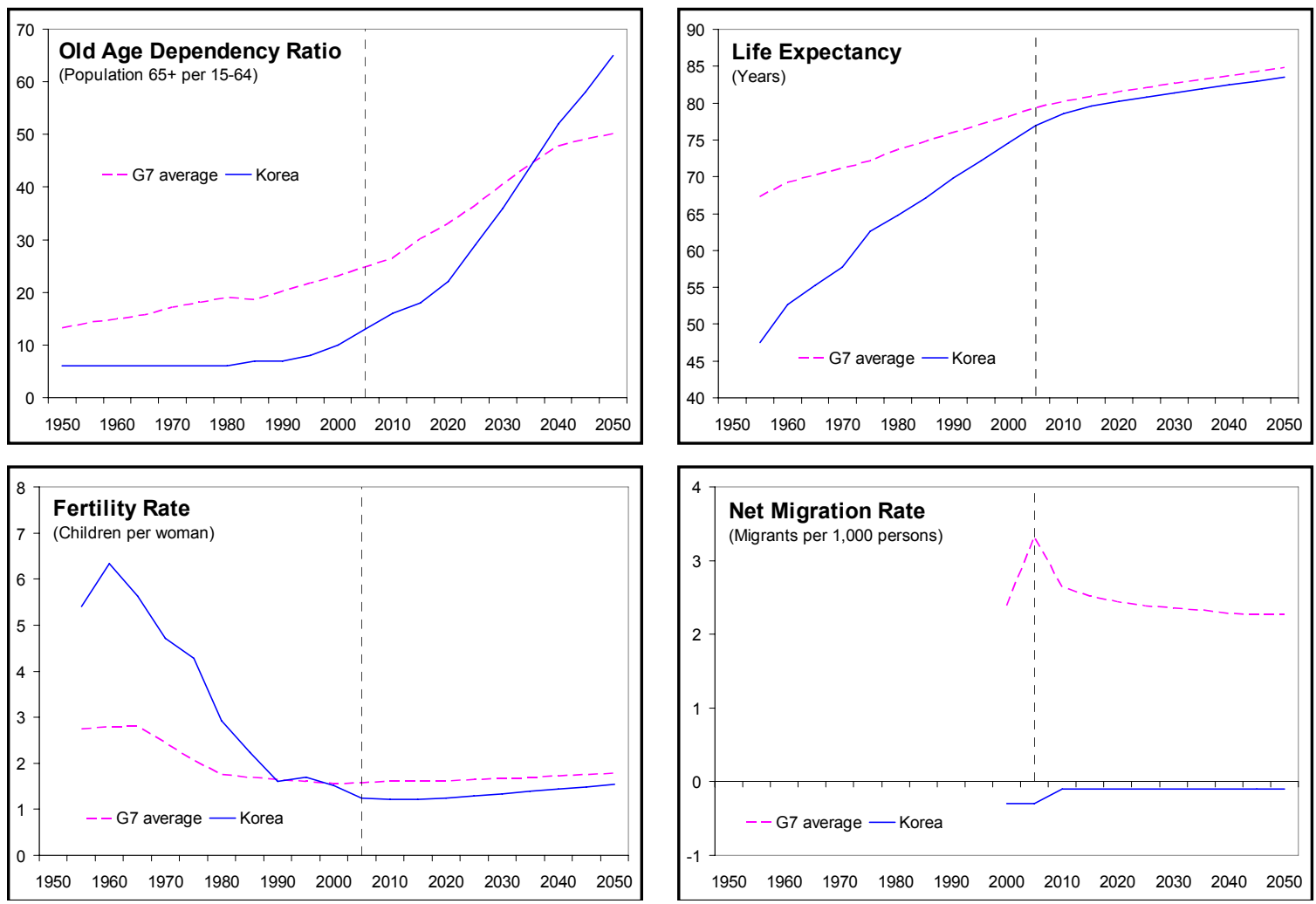

Source: United Nations (2007).

Korea has a number of options to meet the population aging challenge and ensure a sound long-run fiscal position. Most recently, the authorities have decided to lower the replacement ratio to improve the pension system's sustainability. The authorities are also aware of the need to broaden the tax base - as reflected in their draft Directions for Tax Reform - and are contemplating changes to the pension fund's

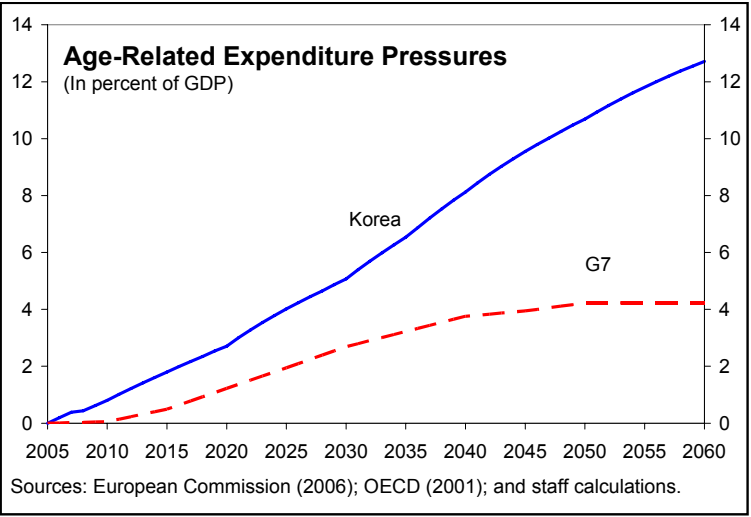
asset management. In addition, reforms could be implemented in the health care sector, non-age-related expenditure growth could be restrained, and, if necessary, once the gains from base broadening are exhausted, some tax rates could be raised. The next sections discuss what these options would imply for Korea's economy. 


\section{Applying the Global Fiscal Model to Korea}

The Global Fiscal Model is a four-country dynamic general equilibrium model based on the New Open Economy Macroeconomics (NOEM) tradition, designed to examine fiscal policy issues. ${ }^{5}$ It is particularly suited to studying temporary or permanent changes in taxes or expenditures, whether rapid or gradual as in the case of age-related expenditure pressures. The GFM analyzes the impact of fiscal policy on real activity through both aggregate demand and supply channels. Aggregate demand responses result from the absence of debtneutrality and consumers' impatience. Aggregate supply responses arise from the distortionary effects of taxation. To allow for thorough fiscal policy analysis, the GFM extends the NOEM framework by introducing non-Ricardian features via three distinct channels:

- Households have finite horizons. As a result, even temporary changes in fiscal policy affect consumption patterns, since any offsetting action required by the government's intertemporal budget constraint is (perceived to be) borne by future generations and there is no bequest motive.

- A fraction of households are liquidity-constrained and consume all their disposable income every period and thereby respond immediately to fiscal policy initiatives that change their disposable income.

- Labor and capital taxes affect incentives to consume and invest, and are thus distortionary.

The model has a number of other features consistent with general equilibrium models. Consumption and production are characterized by constant elasticity of substitution functions, and firms and workers have some market power so that prices and wages are above their perfectly competitive levels. Both traded and nontraded goods are modeled to allow for a bias toward domestic goods in private or government consumption. Capital and labor are the two factors of production and are used to produce traded and nontraded goods. Fixed capital and labor can move freely between sectors, but are not mobile internationally. Investment is driven by Tobin's Q with adjustment costs, such that firms respond sluggishly to differences between the discounted value of future profits and the market value of the capital stock. There are two kinds of financial assets, government debt (traded internationally) and equity (held domestically). International trade in government debt implies the equalization of nominal interest rates across countries over time. However, real interest rates can differ across countries because of the presence of nontraded goods and home bias in consumption.

\footnotetext{
${ }^{5}$ See Botman, Laxton, Muir and Romanov (2006) for a detailed description of the GFM.
} 
The GFM provides a good platform for discussing the relative merits of alternative fiscal consolidation measures and has been applied to several countries, including Canada, Germany, Japan, the United Kingdom and the United States (see Bayoumi and Botman (2005), Botman and Danninger (2007), Botman et al. (2007), Botman and Honjo (2006), and IMF (2004)). The non-Ricardian structure of the model implies empirically plausible responses of key macroeconomic variables to changes in fiscal policy. The wide-ranging menu of taxes allows a detailed analysis of the composition of adjustment while the strong micro foundations allow consideration of the fundamental determinants of the effects of fiscal policy, such as the response of consumers and producers to changes in fiscal policy, as well as sensitivity to the structure of the economy.

For this paper, the model was calibrated to reflect Korea's macroeconomic features and behavioral parameters chosen on the basis of microeconomic evidence from the literature. ${ }^{6}$

\section{GFM SIMULATION RESULTS}

\section{Baseline Scenario}

Our baseline simulation assumes that the current monetary and fiscal stance- the tax rates and current pension parameters - as well as structural policies related to health and long-term care remain unchanged. This is clearly illustrative, since the Korean government has a deepseated commitment to fiscal prudence and is likely to take a number of corrective policy measures as age-related expenditure pressures mount. However, it is useful as a starting point against which to measure the size of the needed adjustment. In this scenario, as discussed in the next section, the pension fund is projected to start registering deficits from 2044 and its assets depleted by 2060, requiring the central budget to transfer funds to the pension system to meet pension obligations over the long run. In addition, public health and long-term care expenditures are assumed to increase from around 3 percent to 11 percent of GDP by $2060{ }^{7}$ At the same time, potential output growth is, under current policies, likely to fall from around $4 \frac{1}{2}$ percent to 2 percent by 2050, mainly reflecting the shrinking labor force (Chensavasdijai, 2006).

The simulations confirm that adjustment is needed to ensure fiscal sustainability (Figure 2). Without measures, the fiscal deficit would increase steadily, reflecting debt-financed expenditure increases and growing interest payments, and the debt path would enter an unsustainable upward trend. This fiscal stance would lead to other imbalances, as strong

\footnotetext{
${ }^{6}$ See Appendix for details.

${ }^{7}$ The future public expenditure pressure is broadly similar in magnitude to the aggregate expenditure pressures discussed in the Vision 2030 Report of the government, although in the latter these pressures stem also from a number of factors that are non-age related.
} 
private domestic demand, supported by large public spending, would result in a ballooning current account deficit.

Figure 2. Baseline Scenario
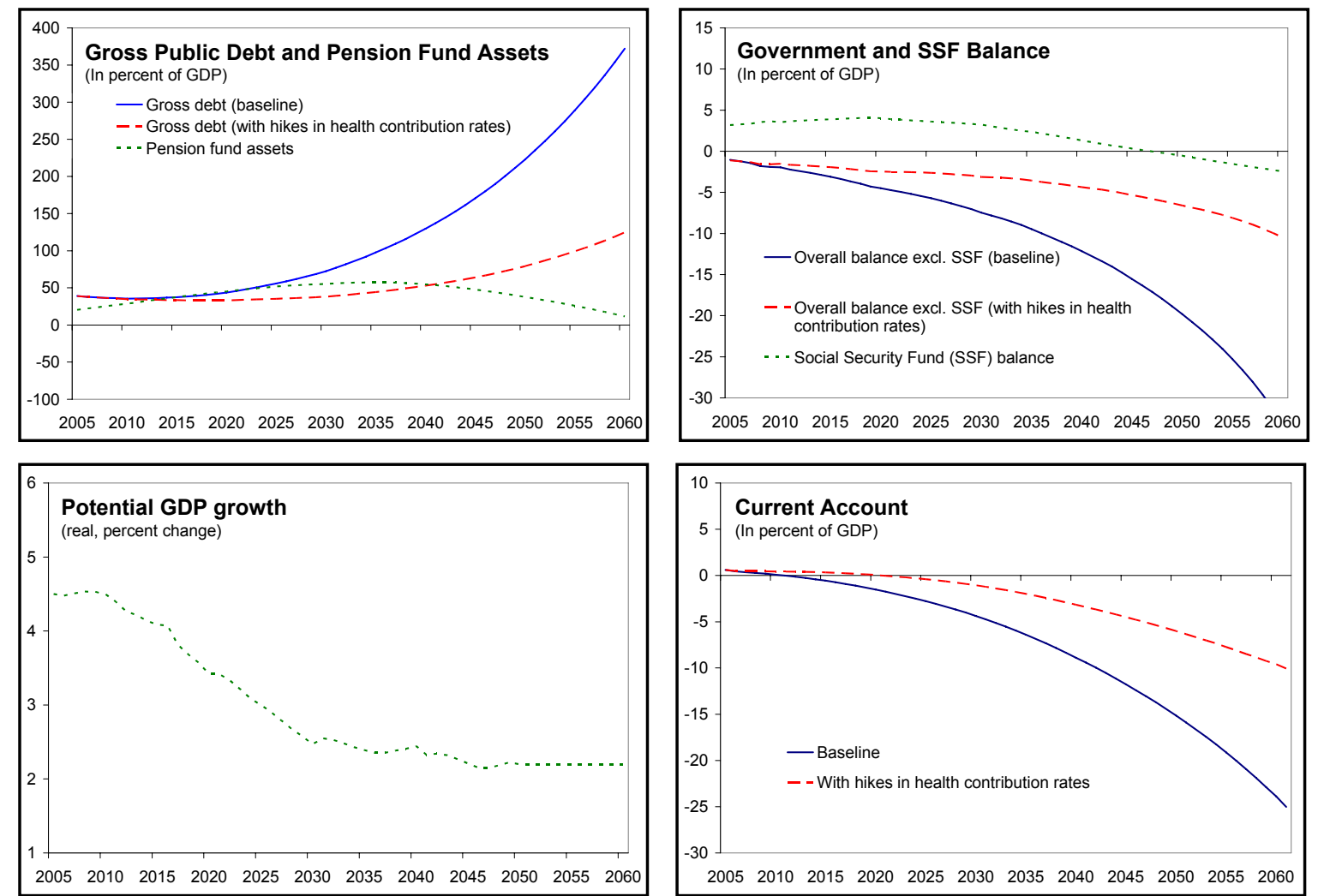

Source: IMF staff estimates and projections.

The next 15 years look deceivingly stable, as the accumulation of assets in the pension fund would allow gross public debt to remain below 50 percent of GDP while the fiscal deficit (excluding social security funds) would remain modest. Moreover, rising fiscal expenditures would temporarily raise employment, wages and growth above potential. But, these developments mask the underlying pressures stemming from demographic changes. Since sufficient assets would not be accumulated to pay for future expenditure, increasing pension and health care expenditures would push the fiscal balance into substantial deficit over the long-term, with adverse consequences for growth, which would enter a downward trajectory relative to potential starting around 2060, with similar declines in consumption and investment.

Another possible representation of the baseline, based on hikes in health care contributions, would lower the projected long-term debt level as well as the fiscal and current account deficits but still place them on a rising trajectory. Since the subsidy element of health care spending is limited to 20 percent by law, hikes in contributions could help to finance a large part of the anticipated rise in health care costs. Based on the assumption that the required 
increases in contributions take place, gross public debt remains lower, at around 80 percent of GDP in 2050, than the more than 200 percent under the previous scenario. While the legal limit on health care subsidies provides additional confidence that necessary policy actions will be taken, discretionary action would still be required. Moreover, the implicit increase in contributions would be large, rising from 3 percent of GDP now to 8 percent of GDP by 2050. In any case, while the precise magnitudes of the effects are somewhat smaller, the implications of this scenario for long-run growth and macroeconomic performance are not qualitatively different from the previous baseline.

\section{Pension Reform}

Korea's National Pension Fund (NPF) is very young, having been introduced in 1988, and its assets will continue to be built up over the medium term, peaking in the mid-2030s. ${ }^{8}$ However, as the number of pension recipients increases, its assets are projected to diminish rapidly.

The recently passed pension reform

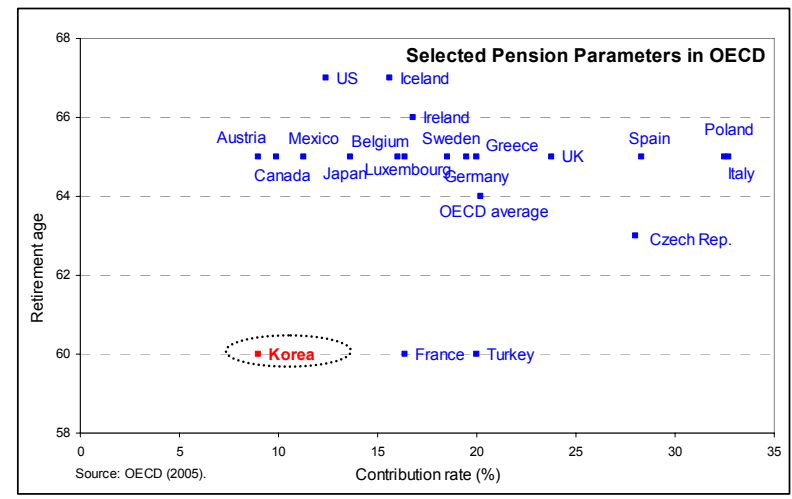
delays, but does not resolve, the problem of the pension fund's depletion. The reform will gradually reduce the pension benefit replacement rate from the current 60 percent of wages to 40 percent by 2028, but does not raise the contribution rate from its current 9 percent. Without further action, the assets of the pension fund would still be depleted, but 13 years later than the pre-reform date of 2047. While the new replacement rate will be quite low, Korea has, together with Australia, the lowest contribution rate among OECD countries, and the retirement age is also well below the OECD average.

Extending the current pension reform proposal by raising contribution rates and/or broadening the payroll tax base could put the pension fund on a permanently sustainable footing. For instance, absent other reforms, a rise in contribution rates from 9 to 18 percent over the period 2011-30 would ensure stabilization of pension fund assets at a positive level and a continuation of surpluses on the pension fund balance (Figure 3). ${ }^{9}$

\footnotetext{
${ }^{8}$ Payment of regular old-age pensions will only begin in 2008 , once the initial participants meet the minimum 20 years of contributions.

${ }^{9}$ These figures are highly sensitive to a number of parameter assumptions, including average return to equity and relative wage growth, and as such should be taken as illustrating the point that significant effort is still needed to put the pension system on a sustainable track.
} 
Figure 3. Pension Reform 1/
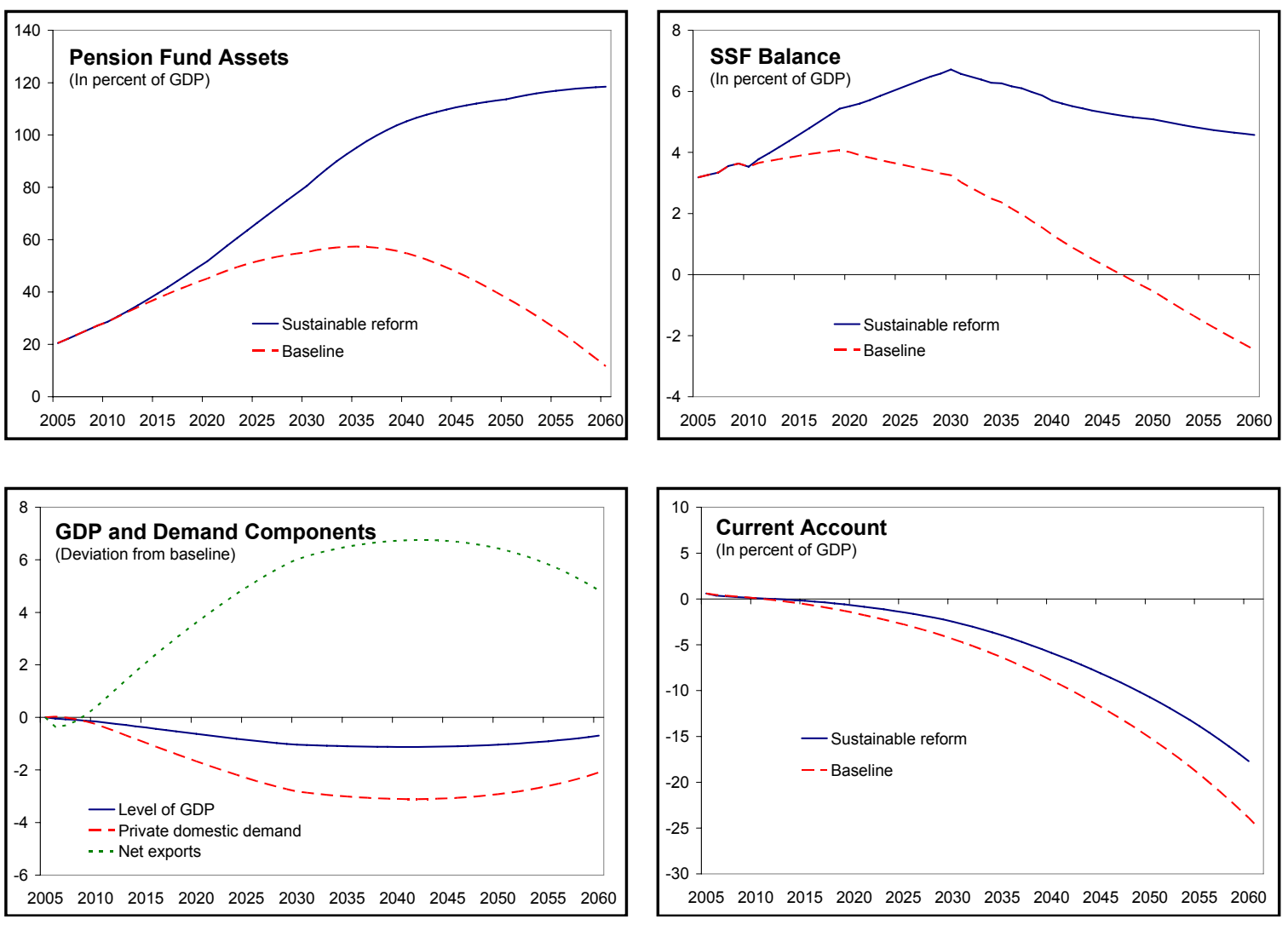

Source: IMF staff estimates and projections.

$1 /$ Assumes a rise in pension fund contribution rates from 9 percent to 18 percent over the period 2011-30.

Alternatively, broadening the contribution base toward OECD levels would allow a much more limited contribution hike. Presently, although coverage is notionally universal, only 60 percent of the labor force contribute to the national pensions system (compared to around 85 for the OECD as a whole), largely reflecting the large number of self-employed and nonregular workers. For example, if the contribution base is broadened to about 80 percent during 2008-10, the rate increase needed to ensure pension system sustainability could be limited to 4 percentage points (from 9 to 13 percent, phased in during 2010-25). With this type of pre-funding strategy, a large part of the pension expenditure increases will be financed by the returns on the pension fund assets and there will be no need for further rate hikes. ${ }^{10}$

\footnotetext{
${ }^{10}$ To limit potential concerns about political interference in the allocation of the pension system's assets, the governance and investment policies underpinning their management would need to be carefully designed.
} 
In either of these scenarios, compared to the baseline, the current account improves as domestic demand and GDP are dampened by the higher pension contributions. While growth relative to the baseline is somewhat lower in the medium term since the stimulus from fiscal deficits is lower, it is more stable and closer to potential in the long run.

Assuming that the pension reform is implemented in a sustainable way, however, rising health and long-term care costs are still projected to increase the fiscal deficit, especially after 2025. Further measures to raise revenues, reform the health sector or contain other expenditure, would be needed to ensure a sound long-run fiscal position. As discussed earlier, one route would be to increase health contribution rates. Below, we consider some alternative options which may yield superior long-run macroeconomic outcomes.

\section{Pension reform and increased revenue}

One option is to raise revenue to prevent fiscal deficits from widening (Figure 4). As discussed in Section V, there appears to be considerable scope to raise tax revenues in Korea, in particular via base broadening. One strategy could be to start raising tax revenues-either through base broadening or by raising tax rates - only when the fiscal surplus (including the social security fund) is eliminated, which would shift costs to the next generation. To model this, the effective personal income tax (PIT) rate is assumed to increase gradually starting in 2025 to maintain fiscal balance. ${ }^{11}$ This requires the effective PIT rate to rise by a cumulative 9 percentage points in 20 years - representing a tripling of the effective PIT rate. Under these assumptions, public debt stabilizes at around 70 percent of GDP, and a positive pension fund asset position is maintained. However, higher taxes lead domestic demand and GDP to decline over the medium term relative to the baseline. Over the longer run, however, the bust of the baseline scenario is avoided, and growth is higher and more stable.

Long-term costs to the economy could be significantly lowered by raising taxes earlier and/or faster. ${ }^{12}$ As an illustration, if tax increases are brought forward and accelerated slightly, so that the effective tax rate is allowed to increase continuously from 2010 until 2025, the effective PIT rate hike could be limited to less than 6 percentage points. Relative to the previous scenario, the government maintains a comfortable overall surplus. With the longrun effective tax rate lower when early action is taken, long-run GDP growth is also higher.

\footnotetext{
${ }^{11}$ Base broadening cannot be distinguished from rate increases in the GFM, except in the case of payroll taxes. Hence, our simulations reflect increases in the effective tax rate, which could reflect either of the two, although the behavioral effects on the economy differ.

${ }^{12}$ There may be other arguments in favor of timely action, including political economy considerations, as the elderly will soon represent the majority of the voting public, making it potentially more difficult to implement some reforms; and the possibility that capital markets may anticipate the consequences of long-term pressures and impose penalties - in the form of lower debt ratings, limited access to capital or higher borrowing costs - if they perceive that the government has not done enough to address these concerns.
} 
Figure 4. Pension Reform and Higher Tax Revenues
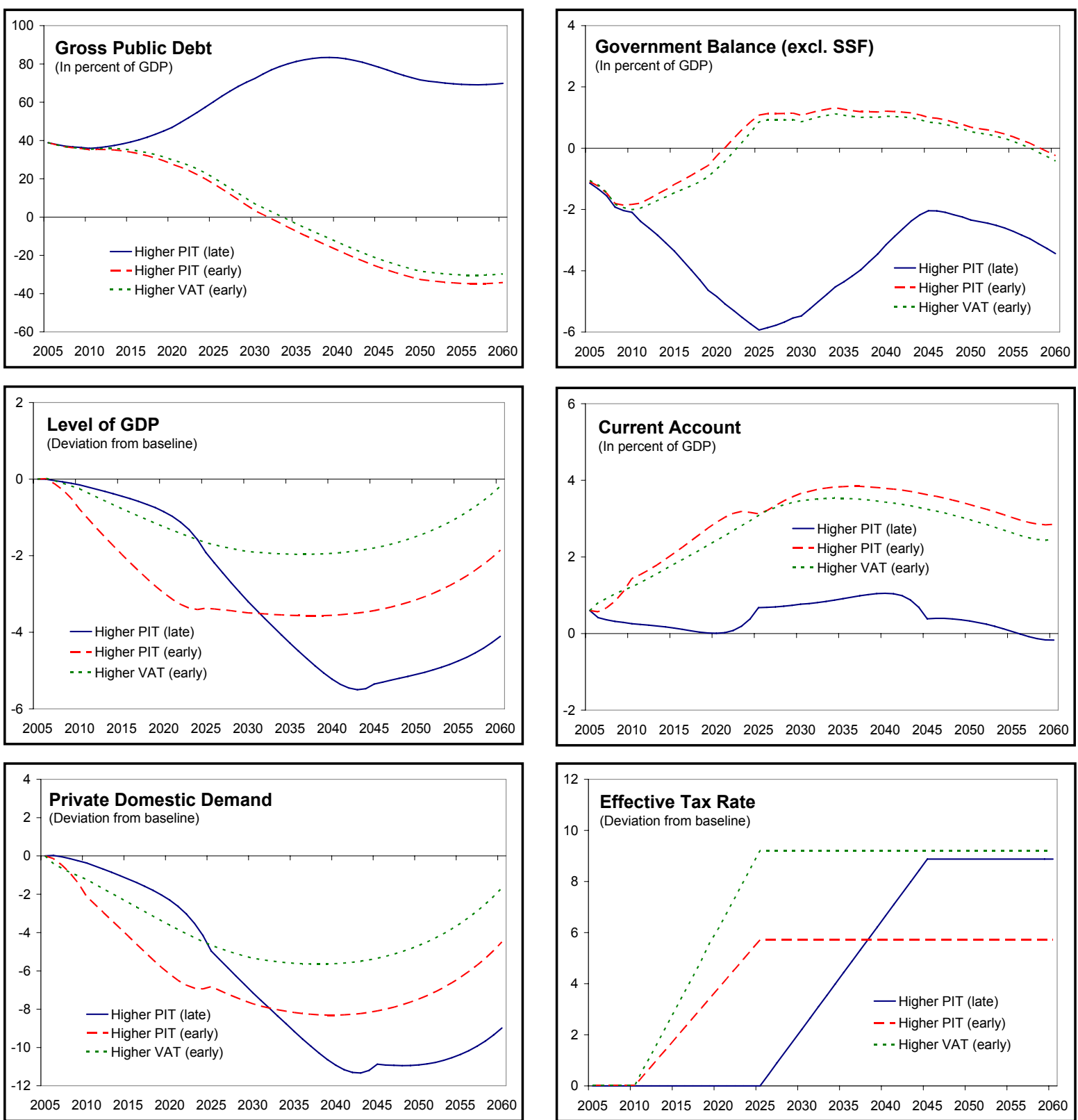

Source: IMF staff estimates and projections. 
Such an "early reform" would allow the government to accumulate more assets to pay for future obligations. This pre-funding strategy implies that part of the future age-related expenditures will be financed through the interest earned on government assets, reducing the size of the needed increase in taxes. In addition, there could be other benefits from acting early, including: more room to accommodate future unanticipated additional adjustment needs, such as the government's desire to increase spending on the social safety net from around 8 percent of GDP presently to the OECD average of 20 percent of GDP by 2030, and spending obligations that may arise from potential reunification with North Korea; and greater inter-generational equity, since both current and later generations bear the adjustment burden.

The type of tax increase also matters. Another option is to consider an effective VAT increase instead of a PIT increase. The advantage of this strategy is that it would reduce distortions, and therefore lower the adverse impact of higher taxes on consumption and growth. ${ }^{13}$ For instance, a gradual rise in the effective VAT rate of 9 percentage points (corresponding to a little more than a doubling of the current effective VAT rate) from 2010 until 2025 helps to stabilize the long-run fiscal position while only leading to modest declines in private consumption and growth relative to the baseline over the medium-term. However, the choice between the PIT and VAT hike is likely to depend on equity as well as efficiency considerations.

\section{Pension reform and expenditure restraint}

An alternative is to restrain expenditure growth to create fiscal space for increasing health care expenditure (Figure 5). This could take the form of cost efficiency gains from health care reform or measures to restrain non-age-related expenditure growth. However, simply allowing health care expenditure to crowd out other expenditure one-to-one would require other expenditure to grow on average by only about 1 percent per annum in real terms, with its share in GDP halved from the current level of close to 20 percent of GDP by 2060. In this context, we consider a scenario where, in addition to a sustainable pension reform, nonhealth expenditure growth is reduced by 4 percentage points of GDP over the period 2011-25, offsetting about half of the increase in health and long-term care expenditure under the baseline.

\footnotetext{
${ }^{13}$ While the VAT also affects the consumption-leisure decision, since accumulated savings are an implicit component of the PIT base, it is less distortionary. This order of efficiency is consistent with evidence from various international studies - see Baylor (2005) for a survey - as well as results of a general equilibrium model for the Canadian economy (Department of Finance, 2004). See Baylor and Beauséjour (2004) for a detailed discussion of the model and results.
} 
Figure 5. Pension Reform and Lower Expenditures
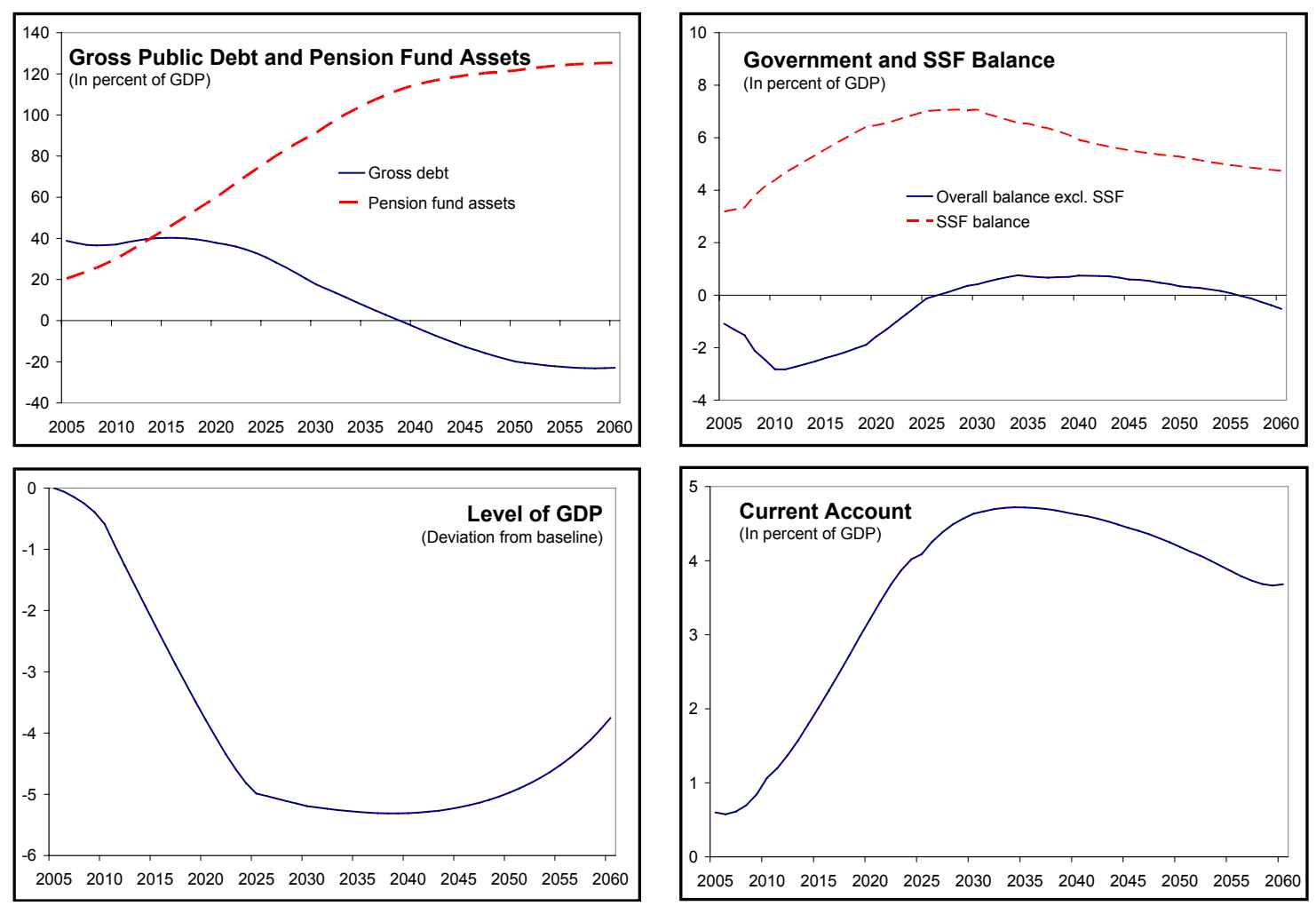

Source: IMF staff estimates and projections.

The results again show that responding early has significant benefits. With early action, this expenditure adjustment is sufficient to stabilize debt and thereby ensure a sound long-term fiscal position. Cost saving measures implemented in the next 15 years could ensure a sound long-term fiscal position without any need to increase taxes, because the return on assets accumulated early on would help pay later for the increased health care costs. The macroeconomic implications are also positive: domestic demand recovers and the current account remains in surplus. However, relying solely on expenditure cuts may not be feasible, as public spending in Korea is already relatively low and additional long-term spending pressures, for higher social safety net spending and potential reunification with North Korea, could be looming.

\section{A combination of policies}

Finally, the government may prefer to implement a combination of more modest policies in each of the areas mentioned above (Figure 6). As an illustration, we consider a combination of pension reform, higher taxes and expenditure restraint, consisting of a pension contribution rate hike together with some payroll base broadening; limited hikes in the 
Figure 6. Pension Reform and a Policy Mix
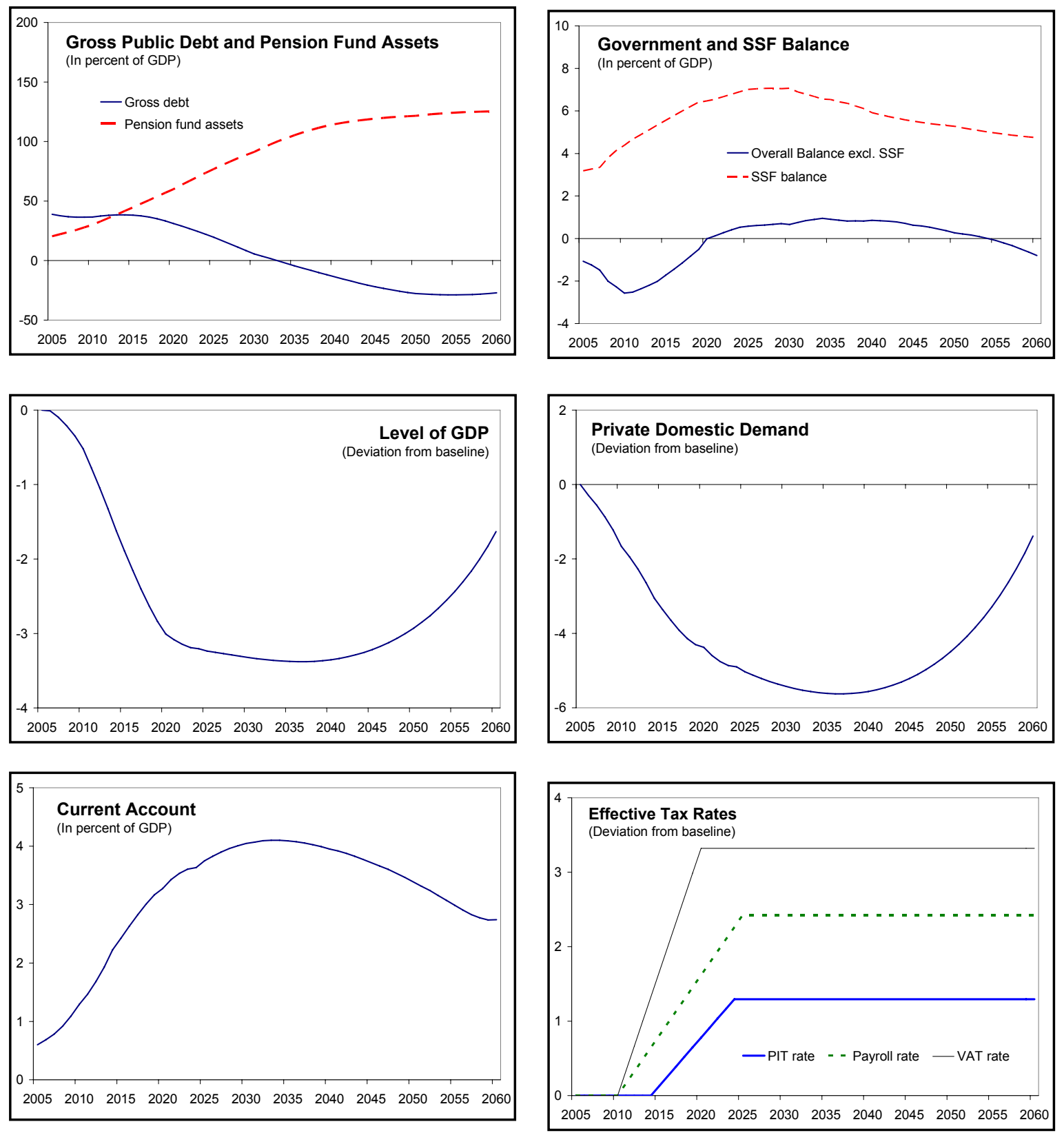

Source: IMF staff estimates and projections. 
effective VAT and PIT rates; and a slowing of non-age-related expenditure growth. ${ }^{14}$ This could be particularly attractive if making large reforms in any one area would be difficult politically. Such a strategy could also have the benefit of equalizing distortions at the margin.

Combining these policies does not change the main conclusions, and, if anything, the macroeconomic effects are generally superior: as long as the fiscal stance is placed on a sustainable path at an early stage, the boom-bust of the baselines is avoided as the pickup in GDP and the recovery in consumption and investment are sustained over the long term, and the current account registers a moderate surplus.

\section{Policy Options For ACHIEVIng The REQuiRed AdJUSTMENT}

While the GFM provides insights into the scope of the fiscal challenges that Korea faces and suggests broad solutions, this section discusses more concrete policy responses. Compared with most other aging economies, Korea benefits from a number of favorable initial conditions, notably currently high rates of economic growth, considerable scope for increasing tax revenue, and a low level of public debt. This provides more degrees of freedom in dealing with age-related fiscal pressures, and some specific recommendations, in addition to the pension reform possibilities considered earlier, are discussed below.

\section{Revenue Measures}

First, there is considerable scope to boost tax revenue collections to accommodate Korea's future spending needs. At around 25 percent, the general government revenue-to-GDP ratio is low relative to most OECD countries. For all major taxes in Korea, there is significant room for increasing the resource envelope through base broadening, even without increases in tax rates. Key options

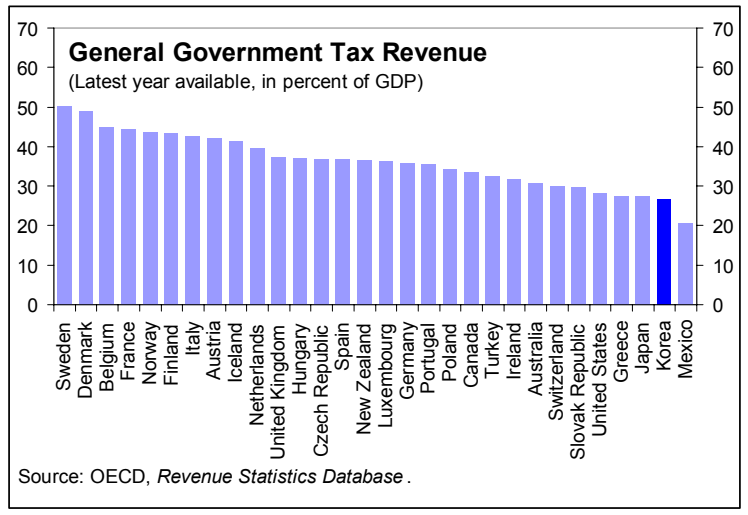
include:

\footnotetext{
${ }^{14}$ More specifically, the scenario assumes a payroll base broadening from 60 to 80 percent of the labor force during 2008-10 followed by a pension contribution rate hike from 9 percent to 13 percent during 2010-25; an effective VAT rate increase of around 31/2 percentage points during 2011-20 and an effective PIT rate increase of around 1 1/2 percentage points during 2016-25; and a cut in total expenditure growth of $1 \frac{1}{2}$ percentage points of GDP during 2011-20.
} 
- Personal income tax (PIT). While personal income tax rates in Korea are broadly in line with those in most countries, PIT yields are very low: accounting for roughly 3 percent of GDP and 14 percent of total tax revenue, compared to an OECD average of 10 and 26 percent, respectively. A key reason for this divergence is that relatively few people in Korea pay PIT: in 2003, the

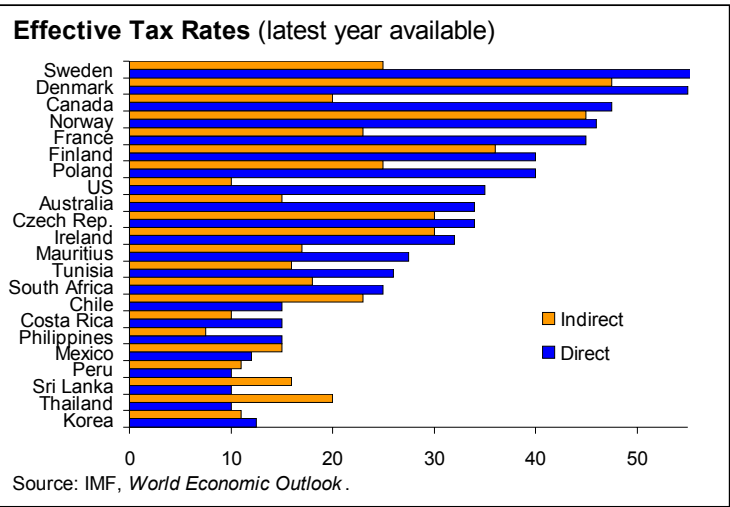
bottom 80 percent of wage and salary employees in the tax system accounted for only 10 percent of taxable income, while the bottom half had virtually no taxable income. This partly reflects the generous wage deduction ${ }^{15}$, special wage credits and the large number of allowable exemptions - including for insurance premiums, medical expenses, and education expenses - which are not subject to an overall ceiling and have significantly reduced the potential tax base. Capping, and ultimately eliminating, some of these deductions and honoring all existing related sunset clauses would help to broaden the PIT base. Moreover, it is suspected that many employees, particularly selfemployed and nonregular workers, do not file returns or understate incomes. ${ }^{16}$ In this context, improving tax administration by intensifying the auditing of the self-employed and strengthening penalties for misreporting income could also help.

- Corporate income tax (CIT). Corporate income tax is a core source of revenue in Korea, accounting for 3 percent of GDP or 14 percent of total taxes, the latter the fourth largest among OECD countries. This makes it important to safeguard this source of revenue by limiting tax incentives. In this context, honoring sunset provisions that exist for the elimination of various CIT incentives and introducing similar clauses for other special schemes (including those related to the various zones for FDI) would help. In addition, publishing on a regular basis ex post estimates and projections of tax expenditures would enhance fiscal transparency and contribute to the public debate on the use of tax exemptions. More generally, efforts should be made to establish a simple and credible CIT regime that is supportive of investment in general, rather than specific activities that are promoted by tax incentives.

\footnotetext{
${ }^{15}$ The wage deduction declines progressively as earnings increase: it is 100 percent for annual earnings of less than 5 million won (equivalent to an exempt amount), and declines in four steps to 5 percent for earnings above 45 million won.

${ }^{16}$ Unlike employees, self-employed workers must pay the full 9 percent contribution rate themselves, so that evasion is more attractive. With nearly two-thirds of Korea's labor force either self-employed or working or short-term irregular employees, enforcing compliance is difficult.
} 
- VAT and excises. Korea makes relatively heavy use of consumption taxes, which raise over one-third of all tax revenue. However, the VAT rate of 10 percent compares to an OECD average of around 18 percent, and the VAT yield is around $4 \frac{1}{2}$ percent of GDP, compared with the OECD average of 7 percent. While the Korean

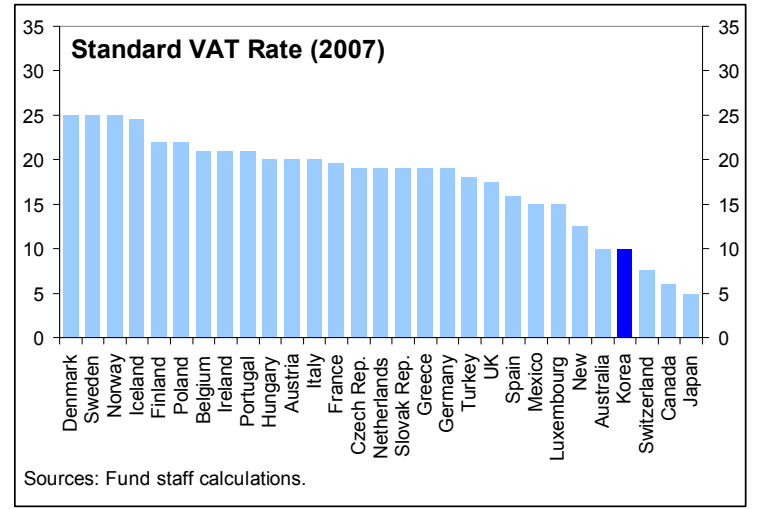
VAT is well designed, base broadening in line with international best practice could be a potentially significant source of additional revenue. In particular, there is scope for re-examining some of the less standard zero rates and exemptions - such as zero rates on suppliers to exporters, machinery, agricultural and fishing inputs, and exemptions on unprocessed foods and agricultural and food products, finance and insurance services, medical, health, and education services - with a view to their elimination. At the same time, payments under social assistance programs such as the Basic Minimum Livelihood Guarantee and the planned earned income tax credit could be adjusted to offset any adverse impact on the most vulnerable. In the longer run, when gains from base broadening are exhausted, consideration could also be given to raising the VAT rate.

The authorities' own preliminary plans, as described in their draft Directions for Tax Reform, are broadly in line with these recommendations. International experience suggests that such revenue measures can help to facilitate and sustain large fiscal adjustments. Enhancing revenues, typically by broadening income taxes and improving tax administration, has been an important strategy in a number of countries that have successfully undertaken large fiscal consolidations in recent times ${ }^{17}$, particularly in countries with low initial revenue-to-GDP ratios and where the pace of adjustment was more gradual. ${ }^{18}$ For example, Canada, Finland and New Zealand reduced personal and corporate tax rates while eliminating exemptions and taxing previously nontaxed income sources. A number of countries also improved tax administration, including Russia and South Africa. Reassuringly, their experience suggests that there is no necessary conflict between adjustment and macroeconomic performanceindeed, large adjustments generally seem to have positive macroeconomic impacts, especially in the case of more gradual approaches.

\footnotetext{
${ }^{17}$ Some recent work by the IMF examines 300 cases of large fiscal consolidation, many involving adjustment over prolonged periods (IMF, 2006).

${ }^{18}$ Related work by Gupta et al. (2003) finds that expenditure-based adjustments are not in themselves sufficient to maintain healthy public finances over the medium-term; efforts are also needed on the revenue side.
} 


\section{Expenditure Measures}

Second, although the scope for expenditure-based responses appears more limited, greater efficiency and discipline with respect to non-age-related spending would also help. About 40 percent of total central government expenditure is non-age-related in the median OECD country, compared to nearly 75 percent in Korea. In particular, Korea allocates a relatively large share of GDP to public investment and economic affairs relative to most OECD economies. In the final analysis, however, the scope for expenditure reallocation appears limited - in particular as public spending is already relatively low in Korea and spending increases for the social safety net, and possibly for reunification with North Korea, may eventually be required.

At the same time, the ability to address future spending pressures will rely critically on adopting effective budgeting and public expenditure management systems. While a range of reforms to improve the efficiency of public expenditure have been attempted over the last two decades, progress has been uneven. In particular, Korea's budget lacks transparency due to its highly fragmented nature (the 2006 budget comprised of one general account, 25 special funds and 55 public funds), weaknesses in the coverage and methodology of the consolidated government budget, the use of a cash-basis accounting, the lack of ex ante estimates of tax expenditures and excessive earmarking.

\section{Building Consensus for Reform}

Finally, there may be a role for publishing a regular long-term fiscal report to help address long-run challenges in a comprehensive manner. A number of economies, particularly those confronting population aging pressures, routinely embed a medium-term framework in their budget processes. Four countries-Australia, New Zealand, the United Kingdom and the United States - stand out in this regard, underpinned by long-term projections covering up to 50 years. Similarly, the European Commission publishes a comprehensive aging report for all EU member states, assessing fiscal sustainability, on an annual basis. Overall, their experiences suggest the desirability of examining both the long-term consequences of policy choices made today and the broad range of risks to which the public finances may be exposed. The latter typically involves identifying and classifying fiscal risks, their sources, and, where possible, the probabilities associated with their occurrence and their associated fiscal costs. Such reports can help to stimulate public debate and an awareness of looming pressures that weigh on the conduct of fiscal policy, making it easier to build consensus on needed reforms.

Korea has begun to extend the horizon considered in its official documents in recent years, but more could be done. Recognizing the need to look beyond the current fiscal year position, the National Fiscal Management Act was passed in September 2006, under which five-year plans featuring fiscal projections and setting aggregate budget targets are being prepared. A summary of longer term economic and policy directions is also presented in the 
Vision 2030 report. Looking ahead, further efforts are needed to integrate long-run issues more systematically into the policy framework, notably by projecting the long-term fiscal consequences of existing policies (bottom-up approach) as well as quantifying the changes in revenue and expenditure that would be needed to achieve certain pre-specified fiscal objectives, such as maintaining some desired level of public debt (top-down approach). Under the latter, a range of scenarios could be presented, each capturing a different manner in which spending and taxes can be adjusted, and illustrating trade-offs that are likely to be faced.

\section{Conclusion}

As a result of rising longevity and falling fertility rates, Korea is facing an unprecedented demographic shift. The population will age very rapidly in the coming decades, and transform from one of the youngest in the OECD to one of the oldest in record time. This dramatic change will put tremendous pressure on the pension system and health and longterm care expenditures. Against this backdrop, a number of important policy implications emerge from our analysis:

First, ensuring a sound long-run fiscal position will require some adjustment. In the absence of a policy response, both the fiscal deficit and debt would accelerate in the long run, the share of consumption and investment in output would continually decline and the current account deficit would grow rapidly, with adverse consequences for long-term growth.

Second, acting early is key. While Korea benefits from several favorable initial conditions compared to other economies facing age-related fiscal pressures, the unprecedented speed of its demographic transition and the confluence of long-term fiscal pressures that it facesnotable spending obligations related to the social safety net and potential reunification with North Korea-leave a relatively narrow window of opportunity. In this context, there are several benefits from acting early and pre-funding the fiscal costs of aging, notably the measures required would be relatively modest, long-run macroeconomic outcomes would be superior, and there would be more room to accommodate additional future adjustment needs.

Third, addressing Korea's long-term fiscal challenges will necessitate reform in a number of areas: in addition to pension reform, there is considerable scope for fiscal consolidation by increasing tax revenue through base broadening (and, if necessary, rate hikes) and improved administration, and some room for reducing non-age-related spending and raising spending efficiency. Finally, the publication of a regular long-term fiscal report could help to communicate underlying fiscal pressures to the public and build consensus for these reforms. 


\section{APPENDIX: CALIBRATING THE GFM FOR KOREA}

The model is calibrated to reflect the macroeconomic features of Korea. In particular, the ratios of consumption, investment, government spending, wage income, and income from capital relative to GDP are set to their current values. Similarly, key fiscal variablesrevenue to GDP ratios from taxation of corporate, labor, and personal income and consumption tax, as well as government debt and current government spending-have been calibrated to Korea's fiscal structure. In addition, the calibration reflects the trading patterns between Korea, the Euro Area, United States, and the rest of the world.

The calibration of behavioral parameters is based on microeconomic evidence found in the literature. ${ }^{19}$ These include parameters characterizing real rigidities in investment, markups for firms and workers, the elasticity of labor supply to after-tax wages, the elasticity of substitution between labor and capital, the elasticity of intertemporal substitution, and the rate of time preference. In particular, the following calibration method was used:

- The baseline value of the sensitivity of labor supply to the real after-tax wage is equal to -0.05 , which is at the low-end of those found by microeconomic studies.

- The elasticity of substitution between labor and capital in the production function equals -0.75 .

- The baseline value for the elasticity of intertemporal substitution is 0.33 . This parameter describes the sensitivity of consumption to changes in the real interest rate.

- The wedge between the rate of time preference and the yield on government bonds determines consumers' degree of impatience and has not been subject to extensive microeconomic analysis. We have set the baseline value of the wedge to 4 percent (corresponding to a planning horizon of 25 years).

- The baseline assumes that 40 percent of consumers are liquidity constrained (i.e., excluded from participating in financial markets). As these consumers have no wealth, these households consume a quarter of aggregate consumption.

- The baseline assumes that the markup over marginal cost in the tradable sector equals 11 percent and in the nontradable sector equals 14 percent.

- The baseline expenditure projections are based on the assumption that all non-age-related expenditure remains constant in percent of GDP. In addition, pension expenditure increases along the lines of Moon (2003) adjusted for the 2007 pension reform, and health care and long-term care expenditure gradually increases (linearly, and broadly in line with the change in old-age dependency ratio) from the current level to the level predicted by OECD (2006a) by 2060.

${ }^{19}$ Other structural parameters have been calibrated using evidence from Laxton and Pesenti (2003) and Batini et al. (2005). 


\begin{tabular}{|c|c|c|c|c|}
\hline \multicolumn{5}{|c|}{ Table A.1. Korea: Key Macroeconomic Variables in the Initial Steady State } \\
\hline \multicolumn{5}{|c|}{ National expenditure accounts at market prices } \\
\hline Expenditure ratios & \multicolumn{4}{|c|}{ Factor Incomes } \\
\hline Consumption & 55.6 & \multicolumn{2}{|c|}{ Capital } & 44.1 \\
\hline Government consumption & 14.8 & \multicolumn{2}{|c|}{ Labor } & 55.9 \\
\hline Investment & 26.7 & \multicolumn{2}{|c|}{ Government } & \\
\hline Exports & 41 & \multirow{2}{*}{\multicolumn{2}{|c|}{$\begin{array}{l}\text { Net debt } \\
\text { Gross debt }\end{array}$}} & 18.4 \\
\hline & & & & 36.4 \\
\hline \multicolumn{5}{|c|}{ Tax rates and revenue } \\
\hline Payroll taxes (worker and employer) & \multicolumn{4}{|c|}{ On personal income } \\
\hline Effective & 5.5 & \multicolumn{2}{|c|}{ Effective } & 3.7 \\
\hline As percent of GDP & 4.6 & \multirow{2}{*}{\multicolumn{2}{|c|}{$\begin{array}{l}\text { As percent of GDP } \\
\text { On consumption }\end{array}$}} & 3.3 \\
\hline On corporate income & & & & \\
\hline Effective & 15.5 & \multicolumn{2}{|c|}{ Effective } & 8.3 \\
\hline As percent of GDP & 3.4 & \multicolumn{2}{|c|}{ As percent of GDP } & 4.7 \\
\hline \multicolumn{5}{|c|}{ Trade flow matrix } \\
\hline & Korea & Euro area & United States & Rest of the world \\
\hline GDP (percent share of world nominal output) & 3.0 & 27.0 & 30.0 & 40.0 \\
\hline Total exports & 41.0 & 25.0 & 15.0 & 20.0 \\
\hline To Korea & $\ldots$ & 1.0 & 0.6 & 1.0 \\
\hline To Euro area & 11.4 & $\ldots$ & 9.0 & 2.7 \\
\hline To United States & 12.2 & 10.3 & $\ldots$ & 0.3 \\
\hline To rest of the world & 17.4 & 13.7 & 10.0 & $\ldots$ \\
\hline
\end{tabular}

Table A.2. Korea: Behavioral Assumptions and Key Parameters in the Initial Steady State

$\begin{array}{lr}\text { Planning horizon of consumers } & 25 \text { years } \\ \text { Labor disutility parameters } & 0.95 \\ \text { Fraction of rule-of-thumb consumers } & 0.40 \\ \text { Intertemporal elasticity of substitution } & 0.33 \\ \text { Elasticity of substitution between capital and labor } & 0.75 \\ & \\ \text { Depreciation rate on capital } & \\ \text { Capital adjustment cost parameters } & 0.50 \\ \text { Elasticity of substitution between varieties } & \\ \text { Tradables sector } & 10.00 \\ \text { Price markup over marginal cost } & 1.11 \\ \text { Nontradables sector } & 8.00 \\ \text { Price markup over marginal cost } & 1.14 \\ & \\ \text { Capital share in production tradables sector } & 0.58 \\ \text { Capital share in production nontradables sector } & 0.58 \\ \text { Utility from real money balances } & 0.02 \\ \text { Price stickiness parameters } & 0.00 \\ & \\ \text { Home bias in government consumption } & \text { Yes } \\ \text { Home bias in private consumption } & N o \\ \text { Elasticity of substitution between traded and nontraded goods } & 0.50 \\ \text { Bias towards domestically produced tradable over nontradables } & 0.40\end{array}$

Source: GFM simulations. 


\section{REFERENCES}

Batini, N., B. Jackson, S. Nickell, 2005, “An Open Economy New Keynesian Phillips Curve for the UK," Journal of Monetary Economics 52(6), (September), pp. 1061-1071.

Baylor, M., 2005, "Ranking Tax Distortions in Dynamic General Equilibrium Models: A Survey,” Working Paper 2005-06 (Ottawa: Department of Finance).

— Canadian CGE Model,” Working Paper 2004-10 (Ottawa: Department of Finance).

Bayoumi, T., and D. Botman, 2005, “Jam Today or More Jam Tomorrow? On Cutting Taxes Now Versus Later," in Canada: Selected Issues, IMF Country Report No. 05/116, (Washington: International Monetary Fund).

Botman, D. and S. Danninger, 2007, "Tax Reform and Debt Sustainability in Germany: An Assessment Using the Global Fiscal Model”, IMF Working Paper 07/46 (Washington: International Monetary Fund).

Botman, D., H. Edison and P. N'Diaye, 2007, “Strategies for Fiscal Consolidation in Japan”, IMF Working Paper 07/37 (Washington: International Monetary Fund).

Botman, D., D. Laxton, D. Muir, and A., Romanov, 2006, “A New-Open-Economy-Macro Model for Fiscal Policy Evaluation”, IMF Working Paper 06/45 (Washington: International Monetary Fund).

Botman, D. and K. Honjo, 2006, “Options for Fiscal Consolidation in the United Kingdom”, IMF Working Paper 06/89 (Washington: International Monetary Fund).

Chensavasdijai, V., 2006, "Korea's Transition to a Knowledge-Based Economy: Prospects and Challenges Ahead," in Republic of Korea: Selected Issues, IMF Staff Country Report, No. 06/381 (Washington: International Monetary Fund).

Department of Finance Canada, 2004, “Tax Expenditures and Evaluations” (Ottawa). Available via the Internet: http://www.fin.gc.ca/taxexp/2004/TaxExp04_e.pdf.

European Commission, 2006, "The Impact of Ageing on Public Expenditure: Projections for the EU25 Member States on Pensions, Health Care, Long-Term Care, Education and Unemployment Transfers, 2004-2050," (Brussels).

Feyzioğlu, T., 2006, “Long-term Fiscal Challenges," in Republic of Korea: Selected Issues, IMF Staff Country Report No. 06/381 (Washington: International Monetary Fund). 
Gruenwald, P., 2003, "Options for Pension System Sustainability in Korea," in Republic of Korea: Selected Issues, IMF Staff Country Report, No. 03/80 (Washington: International Monetary Fund).

Gupta, S., E. Baldacci, B. Clements, and E. Tiongson, 2003, "What Sustains Fiscal Consolidations in Emerging Market Countries?”, IMF Working Paper 03/224 (Washington: International Monetary Fund).

Hauner, D., D. Leigh, and M. Skaarup, 2007, "Ensuring Fiscal Sustainability in G-7 Countries”, IMF Working Paper 07/187 (Washington: International Monetary Fund).

International Monetary Fund, 2004, “Advancing Structural Reforms", in World Economic Outlook, April (Washington: International Monetary Fund).

International Monetary Fund, 2006, "Experience with Large Fiscal Adjustments", IMF Occasional Paper No. 246 (Washington: International Monetary Fund).

Laxton, D. and P. Pesenti, 2003, "Monetary Rules for Small, Open, Emerging Economies," Journal of Monetary Economics 50(5), (July), pp. 1109-1146.

Moon, H., 2003, "The Korean Pension System: Current State and Tasks Ahead," mimeo, Korea Development Institute (Seoul).

OECD, 2001, "Fiscal Implications of Age-Related Spending," OECD Economics Department Working Paper No. 305 (Paris: Organization for Economic Co-operation and Development).

— 2005, "Economic Policy Reforms: Going for Growth" (Paris: Organization for Economic Cooperation and Development).

_ 2006a, "Projecting OECD Health and Long-term Care Expenditure: What are the Main Drivers?" Economics Department Working Paper No. 477, ECO/WKP(2006)5 (Paris: Organization for Economic Co-operation and Development).

— 2006b, "Assessing Fiscal Risks through Long-Term Budget Projections," Report No. GOV/PGS/SBO(2006)9/FINAL (Paris: Organization for Economic Co-operation and Development).

— 2007, "OECD Economic Survey of the Euro Area" (Paris: Organization for Economic Co-operation and Development). 
Skaarup, M., 2007, "Population Aging and Fiscal Sustainability in Estonia" in Republic of Estonia: Selected Issues, IMF Staff Country Report No. 07/256 (Washington: International Monetary Fund).

United Nations, 2007, “World Population Prospects: The 2006 Revision” (New York).

Yun, H. S., 2005, Population Aging and Healthcare, eds., Korea Development Institute, (Seoul). 